\title{
Domingo de Soto, early dynamics theorist
}

Jorge Mira-Pérez

Citation: Physics Today 62, 1, 9 (2009); doi: 10.1063/1.3074244

View online: https://doi.org/10.1063/1.3074244

View Table of Contents: https://physicstoday.scitation.org/toc/pto/62/1

Published by the American Institute of Physics

\section{ARTICLES YOU MAY BE INTERESTED IN}

Ideas for Improving Peer Review

Physics Today 56, 11 (2003); https://doi.org/10.1063/1.1634515

Echegaray-Fiscal Scientist and More

Physics Today 53, 76 (2000); https://doi.org/10.1063/1.1306382

Science controversies past and present

Physics Today 64, 39 (2011); https://doi.org/10.1063/PT.3.1295

Imaging technologies need trained practitioners

Physics Today 62, 8 (2009); https://doi.org/10.1063/1.4796976

Beyond quantum jumps: Blinking nanoscale light emitters

Physics Today 62, 34 (2009); https://doi.org/10.1063/1.3086100

Determining Longitude: A Brief History

Physics Today 58, 15 (2005); https://doi.org/10.1063/1.2138398

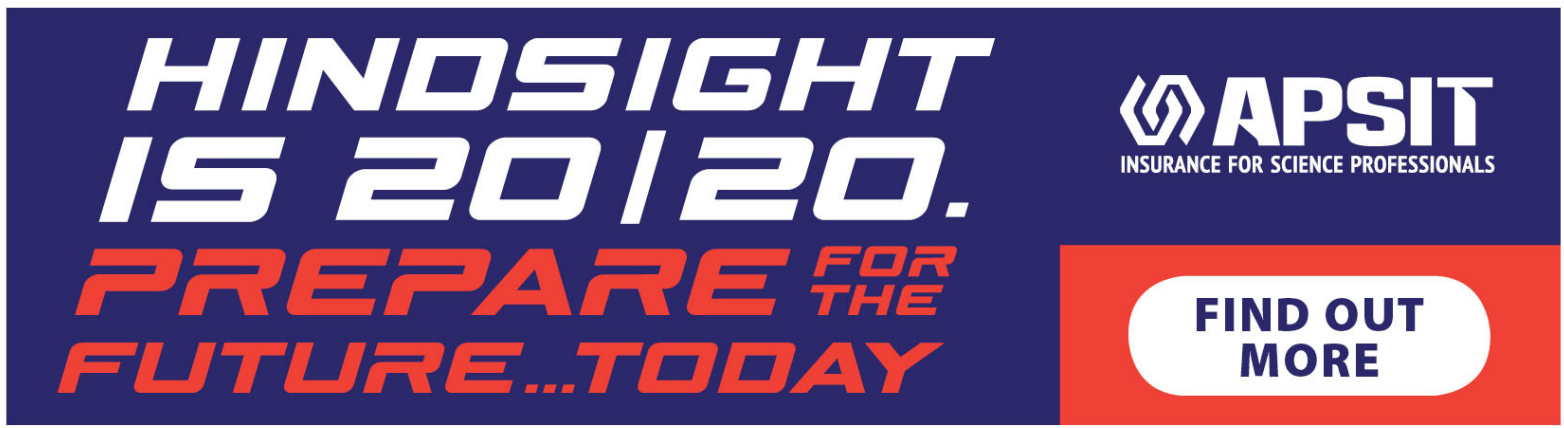


tion. It is interesting to consider where this line of thought might lead.

Robert A. Putnam

(bob.putnam@siemens.com)

Siemens Energy Inc

Orlando, Florida

\section{Domingo de Soto, early dynamics theorist}

The public recognition that innovative scientists receive is nowadays regarded as a fundamental incentive to scientific research. Before Galileo, when scientists were mostly members of the religious orders that controlled medieval universities, acknowledging prior work was not considered so important. For that and other reasons the authors of many significant scientific contributions receded into an obscurity from which only modern scholarship has rescued them. Edith Sylla's interesting article about Thomas Bradwardine's influence on the development of dynamics (PHYsICS TODAY, April 2008, page 51) prompts me to draw attention to what may have been a key original contribution. Spanish Dominican friar Domingo de Soto (1494-1560) clearly stated that a freely falling body undergoes uniform acceleration (motus uniformiter difformis): "For when a heavy object falls through a homogeneous medium from a height, it moves with greater velocity at the end than at the beginning. ... And what is more, the [motion] . . . increases uniformly difformly." ${ }^{11}$

There is no evidence, and it is unlikely, that de Soto's assertion was based on experiment; it was an intuition that must have been suggested by experience, of course, but without any attempt to control that experience so as to extract from it the desired information. In fact, the immediate context of his assertion is not a discussion of the physics of falling bodies but a classification of types of motion; that heavy bodies fall with uniform acceleration is mentioned to illustrate the notion of uniform acceleration, and perhaps only secondarily as a natural-world example of that abstract concept. Be that as it may, the example remained in the literature for scholars of that time to consider (eight editions of de Soto's Quaestiones super octo libros physicorum Aristotelis were published between 1551 and 1613), and it is likely to have been known to Galileo, who mentions de Soto in his Tractatus de Elementis and who attended classes by some of de Soto's intellectual descendants $^{2}$ at the Roman College (now the Pontifical Gregorian University) in Rome.

Furthermore, it was accompanied by an explicit indication that because of the uniformly accelerated nature of its motion, the distance traveled by a freely falling body can be calculated using the mean velocity theorem that had been stated and proved in the 14th century by the Oxford Calculators: for in seeking an appropriate global measure of the velocity of a uniformly accelerating object such as a falling heavy body, de Soto notes that "if the moving object A keeps increasing its velocity from 0 to 8 , it covers just as much space as [another object] B moving with a uniform velocity of 4 in the same period of time." ${ }^{11} \mathrm{He}$ was thus the first to apply mathematics successfully to this physical problem without experimental verification, but in a way that, because it was mathematically precise and physical, constituted an exceptionally clear invitation to experimental verification for such inquisitive minds as were prepared to recognize it.

If de Soto's writings did influence Galileo, as seems quite probable, they may have influenced his thinking on dynamics as well as on kinematics. According to Juan José Pérez Camacho and Ignacio Sols Lucía, de Soto's concept of the resistentia interna of a body foreshadows Galileo's resistenza interna in being intrinsic to the body itself rather than to its medium, and proportional to the weight of the body. ${ }^{3}$ What is less tenable is Pérez Camacho and Sols Lucía's thesis that de Soto considered the velocity $v$ of a moving body to be proportional to the motive force $f$ and inversely proportional to its resistentia interna $r$ - which would be correct in the case of a body accelerated from rest by a constant force, with time as the constant of proportionality and inertial mass as resistentia interna. On the contrary, it seems clear that de Soto's understanding of the relationship among these quantities corresponded not to the formula $v \propto f / r$ but rather to the formula $v \propto \log (f / r)$, first proposed by Bradwardine. ${ }^{4}$ The road from Aristotle to Galileo was long and tortuous, and those who advanced in one dimension often remained stationary or receded in others; de Soto's contribution, though modest, may have been vital.

\section{References}

1. D. de Soto, cited in translation in W. A. Wallace, Isis 59, 384 (1968), p. 400.

2. W. A. Wallace, Domingo de Soto and the Early Galileo: Essays on Intellectual History, Ashgate, Aldershot, UK, and Burlington, VT (2004).

\section{Pssst!}

Need a low-noise amplifier?

Go to www.femto.de to learn more about

... Low-Noise Voltage Amplifier Series DLPVA-100

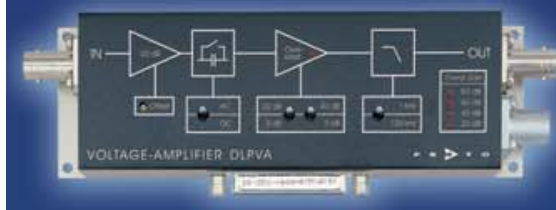

- Input Noise down to $400 \mathrm{pV} / \sqrt{ } \mathrm{Hz}$

- Variable Gain up to $100 \mathrm{~dB}$ (x 100,000)

- Input Impedance up to $1 \mathrm{~T} \Omega$

- Manual and Remote Control

\section{High Speed Gurrent Amplifier -} Series HCA

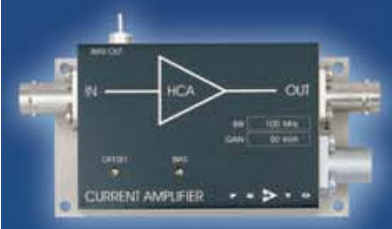

- Bandwidth DC up to $400 \mathrm{MHz}$,

Rise-Time down to 1 ns

- Optimized Models for Large Source

Capacitances up to $2 \mathrm{nF}$

- Ideal for Fast and Large Area

Photodiodes

.. 19" Lock-In Amplifier Board Series LIA-BV(D)-150

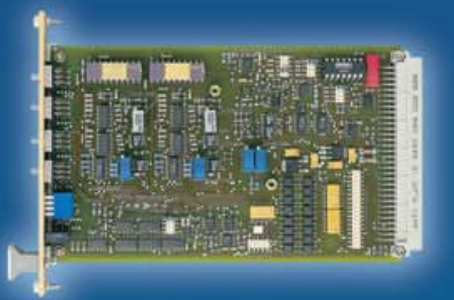

- Working Frequency up to $120 \mathrm{kHz}$

- Phase Independent Output

- Manual and Remote Control

- For Low Cost, Multi-Channel and OEM Applications

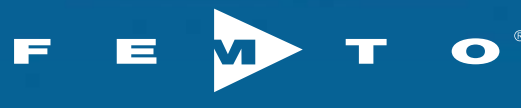

FEMTO ${ }^{\circledR}$ Messtechnik GmbH

Berlin / Germany

info@femto.de r.www.femto.de 


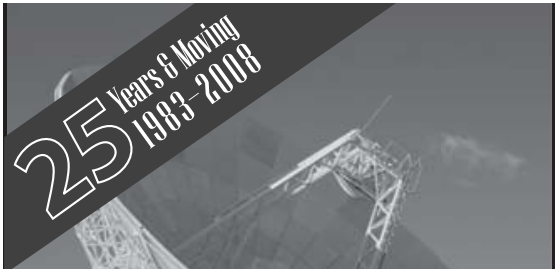

The Easjiest Way to Find Angy far Position?

TILTMETERS

Track angular movement and structural deformation in:

- Particle accelerators

- Beamlines - Antennae

- Aircraft • Fixtures \& machinery

With sensitivities to 5 nanoradians, we offer your best choices for precision tilt measurement.

APPLIED GEOMECHANICS A DIVISION OF PINNACLE TECHNOLOGIES

\section{NANOPOSITIONING} SYSTEMS

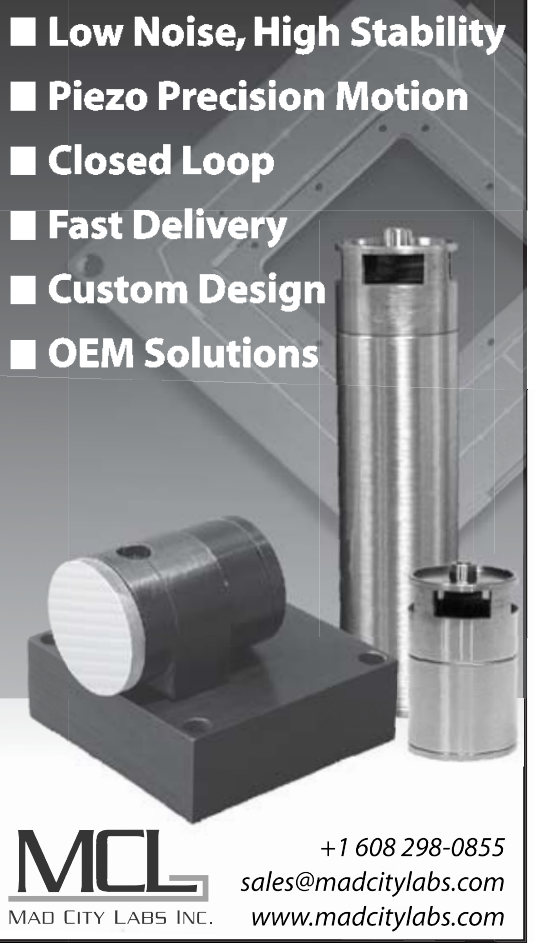

3. J. J. Pérez Camacho, I. Sols Lucía, Rev. Filos. 7(12), 455 (1994), p. 471, available at http://www.ucm.es/BUCM/revistas/fsl/ 00348244/articulos/RESF9494220455A PDF.

4. W. A. Wallace, in Texts and Contexts in Ancient and Medieval Science, E. Sylla, M. McVaugh, eds., Brill, Leiden, the Netherlands (1997), p. 286.

Jorge Mira-Pérez (jorge.mira@usc.es) University of Santiago de Compostela Santiago de Compostela, Spain

\section{Making partners of universities and corporations}

I commend PHYSICS TODAY for its publication of the story "Universities and Industry Find Roadblocks to R\&D Partnering" (PHYSICS TODAY, May 2008, page 20). The author indicates a number of sore spots in university-industry partnerships, especially the negotiation of intellectual property rights in research agreements. The UniversityIndustry Demonstration Partnership, of which I am a past president, has been doing important work in providing a neutral forum, under the auspices of the National Academies, for open and frank discussions between companies and universities about their differences and their commonalities. Issues for discussion include contract negotiations, IP rights in collaborative research, the Bayh-Dole Act, competition from overseas research organizations, Internal Revenue Service policies on the use of buildings financed through tax-exempt bonds, and open source collaborations. The UIDP is interested in improving and streamlining connections between companies and universities for their mutual benefit, the betterment of society, and the country's economic security.

The UIDP strives to remain objective and politically neutral. It fosters the free and open expression of frustrations so they do not silently eat away at mutual trust. The partnership encourages the parties to seek common ground and a shared vision and, when that doesn't work, to look for adequate compromise.

Currently the UIDP has 94 members, one-third of them from industry. Our industrial membership is quite evenly spread over health and life sciences, chemicals and materials, information technology, and consumer products manufacturing. Our university membership is also a mix of land grant colleges and universities, state and other public institutions of higher education, and private institutions.

The UIDP hopes to continue its work and to connect even more companies and academic institutions.

Robert Killoren

(killoren.2@osu.edu)

Ohio State University

Columbus

\section{Correcting the record of manmade VLF radiation}

The story by Charles Day (PHYSICS TODAY, August 2008, page 18) on the effects of very low-frequency radio waves on trapped electrons in the radiation belts describes interesting results obtained on the interaction of manmade VLF radiation with radiationbelt particles. ${ }^{1}$

Unfortunately, the PHYSICS TODAY piece contains several errors.

The absence of radiation in a region of the North Atlantic Ocean is depicted in figure 3 of Day's story-conjugate to the region of radiation detected by the instruments of Jean-André Sauvaud and coworkers ${ }^{1}$ at $700 \mathrm{~km}$ in the South Atlantic Anomaly. That absence is not because of the loss of that radiation by precipitation into the atmosphere but because the northern particle mirror points conjugate to the South Atlantic Anomaly radiation lie at altitudes well above the altitude of the satellite carrying the instruments of Sauvaud's team. - In the South Atlantic in late August and early September 1958, there were three nuclear tests, not one as the author states.

- The first artificial aurora created by a nuclear test was the result of the Teak test in early August 1958, albeit at low latitudes near the Pacific test site of Johnson Island.

- The treaty prohibiting tests in the atmosphere, in space, and under water had a far more complex ancestry than just the results and effects of Starfish Prime, as stated by the author. Widespread concerns regarding the biological effects of fallout and the desire to tamp down the arms race were the major factors that led to the limited test ban treaty of 1963 .

\section{Reference}

1. J.-A. Sauvaud, R. Maggiolo, C. Jacquey, M. Parrot, J.-J. Berthelier, R. J. Gamble, C. J. Rodger, Geophys. Res. Lett. 35, L09101 (2008), doi:10.1029/2008GL033194.

George Paulikas (george.a.paulikas@aero.org) El Segundo, California 